\title{
Glicerina bruta na dieta de ovinos confinados: consumo, digestibilidade, desempenho, medidas morfométricas da carcaça e características da carne
}

\section{Crude glycerin in diets for wethers in feedlot: intake, digestibility, performance, carcass and meat traits}

\author{
Mauriceia Costa Carvalho Barros ${ }^{1 *}$; Jair de Araújo Marques²; \\ Fabiano Ferreira da Silva ${ }^{3}$; Robério Rodrigues Silva ${ }^{3}$; Gilmara Santos Guimarães ${ }^{4}$; \\ Luciano Lemos da Silva ${ }^{4}$; Fabiana Lana de Araújo ${ }^{5}$
}

\section{Resumo}

O objetivo foi avaliar os efeitos dos níveis de glicerina bruta (GB) $(0 ; 2,65 ; 5,33 ; 8,06$ e 10,84\% na base da matéria seca) sobre o consumo, digestibilidade, desempenho, medidas morfométricas da carcaça e qualidade da carne de ovinos terminados em confinamento. Foram utilizados 25 cordeiros mestiços Santa Inês x Dorper, machos, castrados, com peso corporal médio de $24 \pm 2,0 \mathrm{~kg}$, alojados em baias individuais, em delineamento inteiramente casualizado. Os níveis de GB na dieta provocaram efeito linear decrescente $(\mathrm{P}<0,05)$ sobre os consumos de matéria seca, proteína bruta, fibra em detergente neutro e carboidratos não fibrosos. Resultado inverso foi observado sobre o consumo de extrato etéreo. Os coeficientes de digestibilidade da matéria seca e carboidratos não fibrosos reduziram linearmente $(\mathrm{P}<0,05)$ com a adição de glicerina na dieta, enquanto o contrário foi observado para o coeficiente de digestibilidade do extrato etéreo $(\mathrm{P}<0,05)$. Não houve influência $(\mathrm{P}>0,05)$ dos níveis de glicerina sobre o desempenho dos animais. Não foram observadas diferenças $(\mathrm{P}>0,05)$ no peso da carcaça quente, peso da carcaça resfriada, rendimento da carcaça quente, rendimento da carcaça resfriada, perda por resfriamento, estado de engorduramento, comprimento de carcaça, comprimento de perna, profundidade de perna, profundidade de peito, área de olho de lombo, textura, marmoreio e cor. Entretanto, foi observada influência $(\mathrm{P}<0,05)$ dos níveis crescentes de glicerina bruta sobre a conformação da carcaça e espessura de gordura na carcaça. A utilização da glicerina bruta reduziu o consumo de nutrientes dos animais, porém, não influenciou o desempenho e características da carcaça, sendo indicada para utilização na dieta de ovinos em confinamento.

Palavras-chave: Biodiesel, pequenos ruminantes, sistema intensivo

\footnotetext{
Abstract

The aim was to evaluate the effects of crude glycerin levels (CG) $(0,2.65,5.33,8.06$ and $10.84 \%$ in dry matter basis) on intake, digestibility, performance, carcass morphometric measurements and meat

${ }^{1}$ Discente do Curso de Pós-Graduação em Zootecnia, Universidade Estadual do Sudoeste da Bahia, UESB, Itapetinga, BA. E-mail: ceacarvalho@ig.com.br

2 Prof. Adjunto, Dept ${ }^{\circ}$ de Zootecnia, Universidade Federal do Recôncavo da Bahia, UFRB, Campus Cruz das Almas, BA. E-mail: jdmarques@hotmail.com

3 Profs. Drs. do Dept ${ }^{\circ}$ de Zootecnia, UESB, Itapetinga, BA. E-mail: ffsilvauesb@hotmail.com; rrsilva.uesb@hotmail.com

${ }^{4}$ Discentes do Curso de Pós-Graduação em Zootecnia, UESB, Itapetinga, BA. E-mail: gguimaraes114@hotmail.com; lucianolemoszootec@hotmail.com

${ }^{5} \mathrm{Dr}^{\mathrm{a}}$ em Zootecnia, Universidade Federal de Viçosa, UFV, Viçosa, MG. E-mail: fabianalanadearaujo@hotmail.com

* Autor para correspondência
} 
quality of sheep finished in feedlot. Twenty five crossbred Dorper x St. Ines wethers, with $24 \pm 2.0 \mathrm{~kg}$ average weight were housed in individual pens. The experimental design was completely randomized. Levels of CG in gross diet caused a decreasing linear effect $(\mathrm{P}<0.05)$ on dry matter , crude protein, neutral detergent fiber and non-fiber carbohydrates intake. Glycerin levels in the diet showed decreasing linear effect $(\mathrm{P}<0.05)$ on dry matter, crude protein, neutral detergent fiber and non-fibrous carbohydrates intake. Opposite result was observed for lipids intake. Digestibility coefficients of dry matter and nonfibrous carbohydrates decreased linearly $(\mathrm{P}<0.05)$ with glycerin levels, while the opposite was observed to ether extract digestibility coefficient $(\mathrm{P}<0.05)$. There were no effect $(\mathrm{P}>0.05)$ levels of glycerin on animal performance. For morphometric measurements of carcass and meat characteristics, no significant difference $(\mathrm{P}>0.05)$ levels of glycerin for hot carcass weight, chilled carcass weight, hot carcass yield, Chilled carcass yields, loss cooling, state of greasing, carcass length, leg length, depth of leg, chest depth, loin eye area, texture, marbling and color. However, the influence was observed $(\mathrm{P}<0.05)$ of increasing levels of crude glycerin on carcass conformation and carcass fat thickness. The use of crude glycerin reduced nutrient intake of the animals, however, did not influence the performance and carcass characteristics and is indicated its use in the diet of sheep.

Key words: Biodiesel, small ruminants, intensive system

\section{Introdução}

A ovinocultura de corte nordestina, assim como a brasileira, quando praticada em sistema de produção extensivo, é caracterizada por baixos índices produtivos. Esta baixa eficiência produtiva é oriunda, principalmente, das condições edafoclimáticas que, durante parte do ano, imprime ao sistema de produção menor produção de alimento, principalmente, volumoso. Diante deste fato, o confinamento de ovinos para terminação tem recebido, nos últimos anos, crescente adoção em virtude dos benefícios, tais como: redução do tempo para o abate; melhor qualidade das carcaças e peles; manutenção da oferta de alimentos durante o período de escassez de forragens e melhor preço pago pelo produto (BARROSO et al., 2006).

Em tempos de alta de preços de insumos que tornam a fase de terminação de cordeiros em confinamento pouco interessante economicamente, faz-se necessária a busca por fontes alternativas de nutrientes, sendo bastante interessante a utilização de coprodutos da indústria do biodiesel disponíveis na região. Dessa maneira, almeja-se índices zootécnicos superiores, de forma a obter um sistema de produção sustentável.

Segundo ANP (2004), desde o ano de 2008, no Brasil, tornou-se obrigatória a adição de $2 \%$ de biodiesel ao diesel comum. Em julho de 2009, de acordo com a resolução $n^{\circ}$ 2/2009 estabelecida pelo Conselho Nacional de Política Energética (CNPE), a obrigatoriedade da adição do biodiesel ao diesel comum passou de $2 \%$ para $4 \%$. Dessa forma, pode-se constatar o crescimento na produção de biodiesel no país e, consequentemente, de glicerina bruta, pois, de acordo com Dasari et al. (2005), aproximadamente $10 \%$ do peso do óleo ou gordura utilizados para produção do biodiesel é glicerina. A glicerina bruta é um dos coprodutos da produção de biodiesel, e tem surgido como uma opção na alimentação animal, pelo seu menor custo e disponibilidade no mercado.

No processo de produção de biodiesel, ocorre a transesterificação, que consiste na separação da glicerina do óleo vegetal. Essa reação ocorre na presença de um catalisador (hidróxido de sódio ou hidróxido de potássio) e de um álcool de cadeia curta (metanol ou etanol) (FERREIRA, 2009; LAGE et al.,2010). Segundo Oliveira, Carvalho e Souza (2011), em função da variação dos níveis de glicerol presentes na glicerina, esta pode ser classificada como: Glicerina bruta, quando contém baixos níveis de glicerol (40 a 70\%) e pH normalmente elevado (> 12); Glicerina bruta "loira", quando possui de 70 a $90 \%$ de glicerol, apresentando $\mathrm{pH}$ entre 5 e 6; Glicerina grau farmacêutico, que contém mais 
que $99 \%$ de glicerol, sendo utilizada na indústria de cosméticos, higiene pessoal e medicamentos; e Glicerina grau alimentício (food grade), sendo esta totalmente isenta de metanol. De acordo com Lage et al. (2010), a glicerina bruta, que contém $40 \%$ de glicerol, possui como principal impureza os ácidos graxos que não foram convertidos em biodiesel. Dessa forma, o processamento da matéria prima determina o grau de pureza da glicerina.

Doppenberg e Van Der Aar (2007) alertaram que o teor de metanol, presente na glicerina bruta após o processamento, não deve ser superior a $0,5 \%$, valor este que poderá ser evaporado a $65^{\circ} \mathrm{C}$, durante a peletização do alimento. O FDA (2006) recomendou que os níveis de metanol na glicerina sejam inferiores a 150 partes por milhão. Segundo Leão et al. (2012), o metanol é um álcool e tem sido responsável por intoxicações, principalmente em seres humanos e primatas, caracterizadas por acidose metabólicae problemas oculares, apresentando menor toxidade a outrasespécies animais.

Menten, Pereira e Racanicci. (2008) e Berenchtein (2008) demonstraram que a glicerina pode ser considerada um ingrediente energético com potencial para uso em dietas de frangos de corte e suínos em crescimento e terminação. Porém, mais estudos são necessários para avaliar os resultados desse ingrediente em dietas de pequenos ruminantes, para que seja fornecido em quantidades que não comprometam as funções fisiológicas, metabólicas e/ou o desempenho dos animais.

Objetivou-se avaliar o efeito de níveis crescentes de glicerina bruta na dieta sobre o consumo, a digestibilidade dos nutrientes, o desempenho, as medidas morfométricas da carcaça e características da carne de cordeiros terminados em confinamento.

\section{Material e Métodos}

O experimento foi desenvolvido no setor de ovinocultura da Universidade Estadual do Sudoeste da Bahia - UESB, Campus de Itapetinga-BA, durante o período de junho a setembro de 2010.

Foram utilizados 25 cordeiros mestiços Santa Inês x Dorper, com seis meses de idade, machos, castrados, com peso corporal médio de $24 \pm 2,0$ $\mathrm{kg}$, alojados em baias individuais. $\mathrm{O}$ delineamento utilizado foi inteiramente casualizado. Os animais foram distribuídos ao acaso em cinco tratamentos com níveis de $0 ; 2,65 ; 5,33 ; 8,06$ e $10,84 \%$ de glicerina na dieta com base na matéria seca (MS).

As dietas foram fornecidas duas vezes ao dia, às 07:00 e às 16:00 horas na forma de ração completa. O período experimental teve duração de 100 dias, sendo os primeiros 16 dias destinados à adaptação dos animais às instalações, às dietas experimentais e ao manejo, e 84 dias restantes, para avaliação e coleta de dados, divididos em três períodos de 28 dias.

Realizaram-se os ajustes de consumo por meio de pesagem do alimento fornecido e das sobras, permitindo ingestão ad libitum, com sobras de, no máximo, $10 \%$ da quantidade ofertada. A água esteve, permanentemente, à disposição dos animais, fornecida em baldes plásticos.

As dietas foram formuladas de acordo com as recomendações nutricionais do NRC (2007), visando um ganho médio diário de $0,2 \mathrm{~kg}$. O volumoso utilizado foi feno de capim Tifton-85 e os concentrados foram compostos por milho, farelo de soja, ureia, mistura mineral e glicerina (Tabela 1).

Durante os períodos experimentais, foram coletadas amostras dos concentrados e do feno. Semanalmente, foram coletadas amostras de sobras por animal. Posteriormente, foram pré-secas em estufa de circulação forçada de ar a $65^{\circ} \mathrm{C}$, por 72 horas. Após esse período, as amostras foram retiradas da estufa, deixadas à temperatura ambiente por uma hora e pesadas para determinação da matéria pré-seca. Em seguida, as mesmas foram moídas em moinho de facas tipo "Willey", utilizando-se peneira com crivos de $1 \mathrm{~mm}$, e acondicionadas em potes plásticos com tampa e armazenadas para posteriores análises. 
As análises referentes à composição química das amostras de fezes, ofertadas e sobras, foram realizadas no Laboratório de Forragicultura e Pastagem da UESB. Determinaram-se os teores de: matéria seca (MS), matéria orgânica (MO), extrato etéreo (EE), matéria mineral $(\mathrm{MM})$ e proteína bruta (PB), conforme descritas por Silva e Queiroz (2002). Para determinação da fibra em detergente neutro (FDN), foi utilizada a metodologia descrita por Mertens (2002).

Tabela 1. Composição percentual dos ingredientes e composição química das dietas.

\begin{tabular}{lccccc}
\hline \multirow{2}{*}{ Alimentos } & \multicolumn{5}{c}{ Níveis de glicerina (\%MS da dieta) } \\
\cline { 2 - 6 } & 0 & 2,65 & 5,33 & 8,06 & 10,84 \\
\hline Feno de Tifton & 51,78 & 51,76 & 51,75 & 51,74 & 51,73 \\
Farelo de milho & 45,15 & 41,91 & 38,61 & 35,27 & 31,88 \\
Glicerina & 0 & 2,65 & 5,33 & 8,06 & 10,84 \\
Farelo de soja & 2,02 & 2,60 & 3,19 & 3,80 & 4,41 \\
Sal mineral $^{1}$ & 0,34 & 0,34 & 0,35 & 0,35 & 0,35 \\
Ureia $_{\text {Calcário }}$ & 0,35 & 0,35 & 0,35 & 0,35 & 0,36 \\
Fosfato bicálcio & 0,22 & 0,20 & 0,18 & 0,16 & 0,13 \\
\hline Nutrientes & 0,16 & 0,19 & 0,23 & 0,27 & 0,30 \\
\hline MS & & & Composição química $(\%$ na MS) & \\
PB & 90,38 & 90,45 & 90,57 & 90,63 & 90,67 \\
EE & 11,90 & 12,01 & 12,07 & 12,15 & 12,21 \\
FDN & 2,80 & 3,26 & 4,58 & 5,39 & 6,79 \\
FDNcp & 53,07 & 53,16 & 53,20 & 53,33 & 53,35 \\
MO & 47,50 & 47,53 & 47,20 & 47,29 & 46,94 \\
CT & 94,81 & 94,69 & 94,60 & 94,54 & 94,39 \\
CNF & 80,11 & 79,42 & 77,95 & 77,00 & 75,39 \\
CNFcp & 27,03 & 26,26 & 24,74 & 23,67 & 22,03 \\
MM & 32,60 & 31,89 & 30,75 & 29,71 & 28,45 \\
\hline
\end{tabular}

${ }^{1}$ Níveis de garantia (nutrientes/kg): cálcio- $150 \mathrm{~g}$; enxofre-12g; fósforo-65g; magnésio-6.000mg; sódio- 107g; cobre- 100mg; cobalto-175mg; ferro-1000mg; flúor máximo-650mg; iodo-175mg; manganês-1440mg; selênio-27mg e zinco- $6000 \mathrm{mg}$. MS = matéria seca, $\mathrm{PB}=$ proteína bruta, FDN = fibra em detergente neutro, FDNcp = fibra em detergente neutro isenta de cinzas e proteína, $\mathrm{MO}=$ matéria orgânica, $\mathrm{CT}=$ carboidratos totais, $\mathrm{CNF}=$ carboidratos não fibrosos, $\mathrm{CNF}$ cp $=$ carboidratos não fibrosos isentos de cinzas e proteína e $\mathrm{MM}=$ matéria mineral.

Fonte: Elaboração dos autores.

Na Tabela 2, encontra-se a composição físicoquímica da glicerina bruta utilizada para compor os concentrados das dietas.
Tabela 2. Composição físico-química da glicerina bruta utilizada para compor os concentrados da dieta.

\begin{tabular}{lc}
\hline Item $(\% \mathrm{MN}) *$ & Teor (\%) \\
\hline Glicerol & 43,9 \\
Metanol & 6,0 \\
Ácidos graxos totais & 33,6 \\
Água & 9,0 \\
Proteína bruta & 0,2 \\
Matéria mineral & 7,3 \\
Densidade g/cm & 0,95 \\
\hline
\end{tabular}

*Matéria natural

Fonte: Elaboração dos autores. 
Para a determinação do consumo de matéria seca de nutrientes, diariamente, foi registrada a quantidade de alimento oferecido. As sobras eram retiradas e pesadas semanalmente. O consumo voluntário de nutrientes foi obtido pela diferença entre a quantidade oferecida e as sobras.

Para determinação de carboidratos totais (CT), foi usado a seguinte equação, segundo SNIFFEN et al. (1992):

$$
\mathrm{CT}=100-(\% \mathrm{~PB}+\% \mathrm{EE}+\% \mathrm{MM}) .
$$

Os teores de carboidratos não fibrosos (CNF) foram determinados segundo Detmann e Valadares Filho (2010), por meio da equação:

$$
\mathrm{CNF}=100-(\% \mathrm{~PB}+\% \mathrm{EE}+\% \mathrm{MM}+\mathrm{FDNcp})
$$

Do $30^{\circ}$ ao $35^{\circ}$ dias do início do período experimental, foi realizada coleta de fezes para fins de estimar a digestibilidade dos nutrientes, estas foram retiradas diretamente na ampola retal. As amostragens seguiram a seguinte distribuição: No $30^{\circ} \mathrm{dia}(5: 00 \mathrm{~h}), 31^{\circ} \mathrm{dia}(8: 00 \mathrm{~h}), 32^{\circ} \mathrm{dia}(11: 00 \mathrm{~h}), 33^{\circ}$ dia (14:00h), $34^{\circ}$ dia (17:00h) e no $35^{\circ}$ dia (20:00h). Posteriormente aos períodos de coleta, as amostras foram pré-secas em estufa de circulação forçada de ar a $65^{\circ} \mathrm{C}$, por 72 horas, segundo metodologia descrita por Silva e Queiroz (2002). Na sequência, as amostras foram moídas em moinho do tipo Willey (1 $\mathrm{mm}$ ), depois compostas proporcionalmente, com base no peso seco ao ar, por animal/período, e armazenadas em potes plásticos para posterior análise. Para estimativas da excreção fecal diária, foi utilizado como indicador interno a fibra insolúvel ou indigestível em detergente neutro (FDNi), determinada nas amostras do alimento fornecido, sobras e fezes, por intermédio de procedimento de digestibilidadein situ, por 240 horas, segundo metodologia proposta por Casali et al. (2008). Para determinação dos coeficientes de digestibilidade aparente (CDA), foi utilizada a seguinte equação:

$\mathrm{CDA}=[($ nutriente ingerido - nutriente excretado $) /$ nutriente ingerido] x 100
Para determinação do peso corporal inicial (PCI), peso corporal final (PCF) e cálculo do ganho de peso médio diário (GMD) e conversão alimentar (CA), realizaram-se pesagens ao início e final do período experimental, após período de jejum de sólidos por 16 horas. Ao final do período experimental, os animais foram abatidos em abatedouro frigorífico comercial por concussão cerebral; em seguida, foi realizada a sangria, esfola, retirada da cabeça, dos pés e da cauda. Após a evisceração, as carcaças foram pesadas para obtenção do peso de carcaça quente (PCQ) e, logo depois, foram encaminhadas para a câmara frigorífica a $2^{\circ} \mathrm{C}$, onde permaneceram por período de 24 horas, penduradas pela articulação meta-tarsiana, em ganchos apropriados. Decorridas 24 horas, as carcaças foram pesadas para obter-se o peso de carcaça resfriada (PCR). Posteriormente, procederam-se os cálculos dos rendimentos de carcaça quente $(\mathrm{RCQ} \%=\mathrm{PCQ} / \mathrm{PCF} \times 100) \mathrm{e}$ resfriada $(\mathrm{RCR} \%=\mathrm{PCR} / \mathrm{PCF} \times 100)$, assim como a perda de peso por resfriamento $\mathrm{PPR} \%=(\mathrm{PCQ}-$ $\mathrm{PCR}) / \mathrm{PCQ} \times 100$.

Transcorrido o resfriamento, foram aferidas as medidas de comprimento de carcaça (CC), obtida com fita métrica metálica, desde o bordo anterior do osso púbis até o bordo cranial da primeira costela; comprimento de perna (CP), obtido com o auxílio do compasso, sendo considerados pontos do bordo anterior do osso púbis e no ponto médio dos ossos da articulação do tarso, medido-se a abertura do compasso; profundidade de perna (PPE), sendo a maior distância entre o bordo proximal e distal da perna; profundidade de peito (PP), obtido com auxílio de um compasso de pontas metálicas, colocadas entre o dorso na região das cruzes e o osso esterno, em distância máxima, medindo-se a abertura do compasso.

A espessura de gordura (EG) foi tomada na face externa sobre o músculo Longissimus entre a $12^{\mathrm{a}} \mathrm{e}$ $13^{\mathrm{a}}$ costelas, utilizando um paquímetro. Na meiacarcaça esquerda, também foi efetuado um corte transversal, na secção entre a $12^{\mathrm{a}}$ e $13^{\mathrm{a}}$ costelas, 
para mensuração da área de olho de lombo (AOL) do músculo Longissimus, por meio de traçado do contorno do músculo em papel vegetal e, em seguida, utilizou-se a metodologia de contagem de pontos descrita por Luchiari Filho (2000).

Os dados obtidos para classificação de cor, textura, conformação, marmoreio e estado de engorduramento foram obtidos por meio de classificação visual, obedecendo a escala de 0 - 5 pontos, segundo metodologia proposta por Osório (1998).

As análises estatísticas foram realizadas utilizando-se o programa SAEG - Sistema de Análises Estatísticas e Genéticas por meio de análise de variância e regressão, adotandose o nível de 5\% de significância. Os critérios utilizados para escolha dos modelos de regressão consideraram inicialmente a significância para o tratamento, posteriormente consideraram a adequação do modelo aos fenômenos estudados, os valores dos coeficientes de determinação ajustados e a significância dos parâmetros da regressão pelo teste $\mathrm{t}$.

\section{Resultados e Discussão}

Os níveis crescentes de glicerina bruta na dieta influenciaram $(\mathrm{P}<0,05)$ o consumo de matéria seca (CMS, kg/dia; \%PC) (Tabela 3). Resultados semelhantes foram encontrados por Lage et al. (2010), que trabalharam com níveis de inclusão da glicerina $(0,3,6,9$ e 12\%) em substituição ao milho, e por Gunn et al. (2010a), que trabalharam com níveis de inclusão da glicerina $(0,15,30$ e $45 \%$ ) em dietas de ovinos em confinamento. Por outro lado, Pimentel et al. (2014) trabalharam com dietas contendo quatro proporções de substituição do milho grão pela glicerina bruta (GB) corrigida em proteína com coproduto do beneficiamento do milho em $0 ; 33,3 ; 66,6$ e $100 \%$ na base da matéria seca total (MST), correspondendo, respectivamente, a $0 ; 40 ; 80$ e $120 \mathrm{~g}$ de $\mathrm{GB} / \mathrm{kg}$ de MST e relataram que não houve efeito da glicerina sobre o consumo de matéria seca em vacas em lactação.

O consumo de proteína bruta (CPB), fibra em detergente neutro (CFDN) e carboidratos não fibrosos (CCNF) apresentaram efeito linear decrescente $(\mathrm{P}<0,05)$; estes resultados podem ser explicados pelo decréscimo no CMS pelos animais, impedindo que os mesmos consumissem teores mais elevados desses nutrientes (Tabela 3).

Contrariamente, o consumo de extrato etéreo (CEE) apresentou efeito linear crescente $(\mathrm{P}<0,05)$. Este fato pode ser atribuído ao alto teor de ácidos graxos $(33,6 \%)$ presente na glicerina bruta (Tabela 2), o que resultou em dietas com teores crescentes de EE (Tabela 1).

No presente trabalho, o CMS variou de 0,580 $\mathrm{kg} /$ dia (dieta com $10,84 \%$ de glicerina) a 0,943 $\mathrm{kg} /$ dia (dieta controle), essa variação ocorreu, provavelmente, pelo fato dos animais rejeitarem as dietas com níveis crescentes de glicerina. Resultados semelhantes também foram constatados por Lage et al. (2010). 
Tabela 3. Consumo de nutrientes em ovinos alimentados com dietas contendo níveis crescentes de glicerina bruta.

\begin{tabular}{|c|c|c|c|c|c|c|c|c|}
\hline \multirow{2}{*}{ Item $^{8}$} & \multicolumn{5}{|c|}{ Níveis de glicerina (\%) } & \multirow{2}{*}{ Equação } & \multicolumn{2}{|c|}{ Valor de $\mathrm{P}$} \\
\hline & 0 & 2,65 & 5,33 & 8,06 & 10,84 & & $\mathrm{~L}$ & $\mathrm{Q}$ \\
\hline CMS (kg/dia) & 0,943 & 0,786 & 0,764 & 0,715 & 0,580 & 1 & $<0,001$ & 0,964 \\
\hline CMS (\%PC) & 3,1 & 2,9 & 2,8 & 2,5 & 2,2 & 2 & $<0,001$ & 0,262 \\
\hline CPB (kg/dia) & 0,125 & 0,105 & 0,103 & 0,096 & 0,079 & 3 & $<0,001$ & 0,950 \\
\hline CEE (kg/dia) & 0,029 & 0,029 & 0,039 & 0,043 & 0,044 & 4 & $<0,001$ & 0,710 \\
\hline CFDN (kg/dia) & 0,548 & 0,456 & 0,443 & 0,416 & 0,336 & 5 & $<0,001$ & 0,956 \\
\hline CFDN (\%PC) & 1,78 & 1,70 & 1,62 & 1,48 & 1,28 & 6 & $<0,001$ & 0,275 \\
\hline CCNF (kg/dia) & 0,287 & 0,234 & 0,214 & 0,191 & 0,145 & 7 & $<0,001$ & 0,820 \\
\hline
\end{tabular}

L e Q: efeitos de ordem linear e quadrática. ${ }^{1} \ddot{\mathrm{Y}}=0,917738-0,03064 \mathrm{x},\left(\mathrm{R}^{2}=0,93\right) ;{ }^{2} \ddot{\mathrm{Y}}=3,13769-0,0845126 \mathrm{x},\left(\mathrm{R}^{2}=0,94\right) ;{ }^{3} \ddot{\mathrm{Y}}$ $=0,122170-0,00392457 \mathrm{x},\left(\mathrm{R}^{2}=0,92\right) ;{ }^{4} \ddot{\mathrm{Y}}=0,0283551+0,0014613 \mathrm{x},\left(\mathrm{R}^{2}=0,84\right) ;{ }^{5} \ddot{\mathrm{Y}}=0,533170-0,0178737 \mathrm{x},\left(\mathrm{R}^{2}=0,93\right) ;{ }^{6} \ddot{\mathrm{Y}}=$ 1,82127-0,0490808x, $\left(\mathrm{R}^{2}=0,94\right) ;{ }^{7} \mathrm{Y}=0,279294-0,0123193 \mathrm{x},\left(\mathrm{R}^{2}=0,97\right) ;{ }^{8} \mathrm{CMS}=$ consumo de matéria seca, $\% \mathrm{PC}=$ porcentagem peso corporal, $\mathrm{CPB}=$ consumo de proteína bruta, $\mathrm{CEE}=$ consumo de extrato etéreo, $\mathrm{CFDN}=$ consumo de fibra em detergente neutro e CCNF = consumo de carboidratos não fibrosos.

Fonte: Elaboração dos autores.

Os teores de glicerol e metanol $(43,9 \% ; 6 \%$, respectivamente) da glicerina utilizada no presente trabalho foram muito próximos aos utilizados por Lage et al. (2010) (46,48\% de glicerol e 8,66\% de metanol), indicando que a glicerina bruta com teores elevados de glicerol e metanol podem causar rejeição do alimento e, consequentemente, redução no CMS em ovinos.

Estudos com a inclusão de glicerina bruta em pequenos ruminantes, realizados por Gunn et al. (2010a, 2010b); Kerr, Dozier e Bregendahl (2007) e Schroder e Sudekum (2007), não encontraram efeitos de rejeição da glicerina pelos animais, porém, os teores de ácidos graxos e metanol $(<1,0 \%)$ utilizados por esses pesquisadores foram inferiores aos encontrados na glicerina bruta utilizada no presente experimento. Atribui-se esta variação da composição da glicerina bruta ao fato de não haver, por parte da indústria brasileira, maiores preocupações com o processo de separação do biodiesel, o material remanescente que seria o glicerol e os compostos químicos utilizados na produção de biodiesel, resultando no aumento da contaminação da glicerina bruta (LAGE et al., 2010).
Segundo Tyson et al. (2004), o sal e as impurezas nos óleos reciclados e os reagentes usados na transesterificação são os principais problemas da glicerina de biodiesel, pois podem limitar o consumo. Doppenberg e Van Der Aar (2007) observaram que o uso de hidróxido de sódio para catalisar a hidrólise pode se combinar com ácido clorídrico, aumentando o conteúdo de cloreto de sódio na glicerina, podendo ultrapassar $6 \% \mathrm{e}$, assim, restringir a quantidade de glicerina que poderia ser incluída na dieta. Estas informações foram confirmadas por Gunn et al. (2010a), ao avaliarem níveis crescente de glicerina na dieta de ovinos $(0,15,30$ e $45 \%)$. Estes pesquisadores observaram decréscimo no consumo de matéria seca e atribuíram este fato aos elevados teores de sal $(\mathrm{Na}-5,38 \%)$ contidos na glicerina bruta. Gomes et al. (2011), ao avaliarem níveis de glicerina bruta $(0,15$ e $30 \%)$ na dieta de ovinos em confinamento, não observaram influência $(\mathrm{P}>0,05)$ no consumo de matéria seca, porém, os teores de $\mathrm{N}$ presentes na glicerina utilizada foi de $1,3 \%$.

Outro fator que pode ter contribuído para a diminuição do CMS é a intolerância dos microrganismos ruminais a elevados níveis de 
material graxo. O consumo de alimentos comumente decresce, quando os níveis de gordura excedem $6 \%$ MS na dieta (PALMQUIST; JANKINS, 1980). De acordo com Liddle et al. (1985), os lipídios são potentes estimuladores da colecistoquinina e uma das hipóteses é que a colecistoquinina suprime o consumo de alimentos pela inibição do esvaziamento gástrico (MORAN; MCHUGH, 1982). De acordo com Choi e Palmquist (1996), há um aumento de colecistoquinina no plasma, quando as dietas apresentam teores elevados de lipídeos, acarretando em redução na taxa de passagem da digesta,aumentando a distensão do retículo-rúmen. Allen (2000) afirmou que esta distensão promove a estimulação de receptores da colecistoquinina nesses compartimentos do trato gastrintestinal. Dessa forma, os receptores enviam informações via sistema nervoso central, promovendo a redução do apetite e, redução do CMS pelos animais. Observouse que, com o aumento dos níveis de glicerina bruta $(2,65,5,33,8,06$ e $10,84 \%)$, o teor de extrato etéreo na dieta foi elevando-se $(3,26,4,58,5,39$ e 6,79\%), o que pode ter contribuído para o aumento da secreção de colecistoquinina no plasma, reduzindo o CMS.
Portanto, considerando que a glicerina utilizada no presente estudo foi de baixa pureza, acreditase que os níveis de glicerol, metanol e EE na dieta contribuíram de forma isolada ou em conjunto para influenciarem o CMS pelos animais.

Houve influência $(\mathrm{P}<0,05)$ dos níveis crescentes de glicerina bruta na dieta sobre os coeficientes de digestibilidade total da matéria seca (CDMS) e extrato etéreo (CDEE). Por outro lado, Farias et al. (2012) relataram que não encontraram efeito da inclusão de glicerina $(0 ; 2,8 ; 6,1$ e 9,0\% na MS da dieta) sobre os coeficientes de digestibilidade da MS, $\mathrm{PB}, \mathrm{MO}, \mathrm{FDN}, \mathrm{CNF}$ e CT. Entretanto encontraram efeito linear $(\mathrm{P}<0,05)$ sobre a digestibilidade do extrato etéreo.

Os coeficientes de digestibilidade da proteína bruta (CDPB), fibra em detergente neutro corrigido para cinza e proteína (CDFDNcp) e nutrientes digestíveis totais (NDT) não foram influenciados $(\mathrm{P}>0,05)$ pelos níveis crescentes de glicerina bruta na dieta. Entretanto, houve efeito quadrático $(\mathrm{P}<0,05)$ sobre o coeficiente de digestibilidade dos carboidratos não fibrosos (CDCNF), estimandose o nível de $1,43 \%$ de GB; para a digestibilidade máxima de 93,93\% (Tabela 4).

Tabela 4. Digestibilidade aparente de nutrientes em ovinos alimentados com níveis crescentes de glicerina bruta.

\begin{tabular}{|c|c|c|c|c|c|c|c|c|}
\hline \multirow{2}{*}{ Item $^{4}$} & \multicolumn{5}{|c|}{ Níveis de glicerina $(\%)$} & \multirow{2}{*}{ Equação } & \multicolumn{2}{|c|}{ Valor de P } \\
\hline & 0 & 2,65 & 5,33 & 8,06 & 10,84 & & $\mathrm{~L}$ & Q \\
\hline CDMS \% & 62,54 & 61,61 & 60,49 & 56,84 & 59,09 & 1 & $<0,001$ & 0,658 \\
\hline CDPB \% & 67,36 & 65,58 & 59,33 & 60,20 & 61,26 & $\ddot{Y}=62,75$ & 0,028 & 0,242 \\
\hline CDEE \% & 55,85 & 64,22 & 70,84 & 71,27 & 78,98 & 2 & $<0,001$ & 0,588 \\
\hline CDFDNcp \% & 49,69 & 53,42 & 51,47 & 47,47 & 53,67 & $\ddot{Y}=51,14$ & 0,950 & 1,00 \\
\hline CDCNFcp \% & 93,63 & 93,80 & 90,38 & 87,29 & 79,77 & 3 & $<0,001$ & 0,041 \\
\hline NDT \% & 65,66 & 66,82 & 66,55 & 64,34 & 67,43 & $\ddot{Y}=66,16$ & 0,855 & 0,956 \\
\hline
\end{tabular}

L e Q: efeitos de ordem linear e quadrática. ${ }^{1} \ddot{\mathrm{Y}}=63,8836-0,621382 \mathrm{x},\left(\mathrm{R}^{2}=0,71\right) ;{ }^{2} \ddot{\mathrm{Y}}=57,4964+2,00507 \mathrm{x},\left(\mathrm{R}^{2}=0,95\right) ;{ }^{3} \ddot{\mathrm{Y}}=$ $93,5744+0,497465 \mathrm{x}-0,174074 \mathrm{x}^{2},\left(\mathrm{R}^{2}=0,86\right) ;{ }^{4} \mathrm{C}=$ Coeficiente; $\mathrm{D}=$ digestibilidade; $\mathrm{MS}=$ matéria seca; $\mathrm{PB}=$ proteína bruta; $\mathrm{FDNcp}=$ fibra em detergente neutro corrigido para cinzas e proteínas; $\mathrm{EE}=$ extrato etéreo; $\mathrm{CNF}=$ carboidratos não fibrosos e NDT = nutrientes digestíveis totais.

Fonte: Elaboração dos autores. 
O coeficiente de digestibilidade da matéria seca foi influenciado $(\mathrm{P}<0,05 \%)$ pelos níveis de glicerina bruta utilizada nas dietas, devido aos níveis elevados de EE contido nas dietas. Resultados semelhantes foram encontrados por Abdullah, Nawaz e Mohiuddin (2001), ao trabalharem com níveis crescentes de lipídios na alimentação de búfalas lactantes, observando uma redução no consumo e na digestibilidade da matéria seca à medida que elevaram o nível lipídico da dieta.

De acordo com Oliveira et al. (2009), o consumo e a digestibilidade dos nutrientes podem sofrer influência dos níveis de lipídios na dieta, cuja redução na ingestão está relacionada com a formação de uma barreira física nas partículas, que dificulta o ataque microbiano e a ação tóxica do ácido graxo insaturado sobre certas espécies de microrganismos (PALMQUIST, 1991). O processo de biohidrogenação realizado pelos microrganismos do rúmen visa hidrolisar os ácidos graxos insaturados e promover a saturação com o hidrogênio. Estas reações ocorrem para autoproteção dos microrganismos, uma vez que os efeitos maléficos dos ácidos graxos saturados é menor do que o dos insaturados (OLIVEIRA et al., 2009). Entretanto, mesmo com o processo de biohidrogenação, níveis elevados de lipídios podem reduzir o consumo e a digestibilidade, motivo pelo qual as concentrações de extrato etéreo na matéria seca da dieta de ruminantes não devem extrapolar valores acima de 5\% (NRC, 1984).

A digestibilidade do extrato etéreo da dieta com glicerina aumentou de forma linear $(\mathrm{P}<0,05)$, o que pode estar associado ao fato do teor de ácidos graxos da glicerina (Tabela 2) proporcionar maior disponibilização lipídica no intestino delgado para formação das micelas e absorção. Silva et al. (2007) também observaram maior coeficiente de digestibilidade do extrato etéreo em dietas contendo maiores teores de lipídios, para cabras em lactação.

Os níveis de glicerina bruta não influenciaram $(\mathrm{P}>0,05)$ a digestibilidade da proteína bruta, fibra em detergente neutro corrigido para cinzas e proteína e nutrientes digestíveis totais, o que pode ser atribuído à pequena diferença dos teores destes nutrientes na dieta.

No que se refere aos parâmetros de desempenho, não houve influência $(\mathrm{P}>0,05)$ dos níveis de glicerina bruta na dieta sobre o peso corporal final (PCF), ganho médio diário (GMD) e conversão alimentar (CA) (Tabela 5).

Tabela 5. Desempenho de ovinos alimentados com níveis crescentes de glicerina bruta.

\begin{tabular}{|c|c|c|c|c|c|c|c|c|}
\hline \multirow{2}{*}{ Item $^{1}$} & \multicolumn{5}{|c|}{ Níveis de glicerina (\%) } & \multirow{2}{*}{ Equação } & \multicolumn{2}{|c|}{ Valor de $\mathrm{P}$} \\
\hline & 0 & 2,65 & 5,33 & 8,06 & 10,84 & & $\mathrm{~L}$ & Q \\
\hline PCF (kg) & 35,26 & 30,48 & 32,20 & 32,20 & 28,88 & $\ddot{Y}=31,80$ & 0,090 & 0,730 \\
\hline GMD (kg) & 0,105 & 0,083 & 0,101 & 0,093 & 0,066 & $\ddot{Y}=0,090$ & 0,043 & 0,349 \\
\hline $\mathrm{CA}(\mathrm{kg})$ & 9,07 & 11,25 & 8,06 & 7,90 & 9,17 & $\ddot{Y}=9,09$ & 0,843 & 0,638 \\
\hline
\end{tabular}

L e Q: efeitos de ordem linear e quadrática. ${ }^{1} \mathrm{PCF}=$ peso corporal final; GMD = ganho médio diário e CA = conversão alimentar. Fonte: Elaboração dos autores.

Com a redução do CMS, era esperado que os animais apresentassem menor ganho de peso, mas este fato não ocorreu, provavelmente, porque as quantidades de nutrientes das dietas, principalmente energia, foram suficientes para suprir as exigências de mantença dos animais, não influenciando $(\mathrm{P}>0,05)$ no desempenho.

Não foi verificada influência $(\mathrm{P}>0,05)$ dos níveis de glicerina bruta sobre o peso de carcaça quente (PCQ), peso de carcaça resfriada (PCR), 
rendimento de carcaça quente (RCQ), rendimento de carcaça resfriada (RCR), perda por resfriamento (PPR), estado de engorduramento (EEn), comprimento de carcaça (CC), comprimento de perna (CP), profundidade de peito (PP) e profundidade de perna (PPE) à medida que se elevaram os níveis de glicerina na dieta (Tabela 6). Por outro lado, houve influência dos níveis crescentes de glicerina bruta na dieta sobre a conformação (CONF) (Tabela 6).

Tabela 6. Medidas morfométricas da carcaça de ovinos alimentados com níveis crescentes de glicerina bruta.

\begin{tabular}{|c|c|c|c|c|c|c|c|c|}
\hline \multirow{2}{*}{ Item $^{2}$} & \multicolumn{5}{|c|}{ Níveis de glicerina (\%) } & \multirow{2}{*}{ Equação } & \multicolumn{2}{|c|}{ Valor de $\mathrm{P}$} \\
\hline & 0 & 2,65 & 5,33 & 8,06 & 10,84 & & $\mathrm{~L}$ & $\mathrm{Q}$ \\
\hline PCQ (kg) & 17,48 & 14,32 & 14,43 & 15,23 & 13,10 & $\ddot{Y}=14,91$ & 0,051 & 0,525 \\
\hline PCR $(\mathrm{kg})$ & 16,98 & 13,80 & 13,90 & 14,82 & 12,58 & $\ddot{Y}=14,42$ & 0,055 & 0,540 \\
\hline RCQ (\%) & 49,34 & 46,45 & 44,56 & 47,32 & 44,66 & $\ddot{Y}=46,47$ & 0,051 & 0,338 \\
\hline RCR (\%) & 47,92 & 44,66 & 42,88 & 46,07 & 42,84 & $\ddot{Y}=44,87$ & 0,073 & 0,401 \\
\hline PPR $(\%)$ & 2,91 & 3,98 & 3,81 & 2,62 & 4,14 & $\ddot{Y}=3,49$ & 0,577 & 0,929 \\
\hline CONF & 3,7 & 3,1 & 3,3 & 3,0 & 2,7 & 1 & 0,002 & 0,703 \\
\hline EEn & 3,3 & 3,1 & 2,9 & 3,0 & 2,5 & $\ddot{Y}=2,96$ & 0,020 & 0,766 \\
\hline $\mathrm{CC}(\mathrm{cm})$ & 65,40 & 62,20 & 59,75 & 62,75 & 60,40 & $\ddot{Y}=62,10$ & 0,206 & 0,447 \\
\hline $\mathrm{CP}(\mathrm{cm})$ & 32,0 & 29,9 & 31,4 & 32,9 & 29,1 & $\ddot{Y}=31,06$ & 0,307 & 0,451 \\
\hline $\mathrm{PP}(\mathrm{cm})$ & 27,0 & 25,40 & 24,75 & 25,50 & 24,40 & $\ddot{Y}=25,41$ & 0,070 & 0,469 \\
\hline PPE (cm) & 14,70 & 14,10 & 13,87 & 13,75 & 13,20 & $\ddot{Y}=13,92$ & 0,252 & 0,950 \\
\hline
\end{tabular}

L e Q: efeitos de ordem linear e quadrática. ${ }^{1} \ddot{\mathrm{Y}}=3,56229-0,077949 \mathrm{x},\left(\mathrm{R}^{2}=0,82\right) ;{ }^{2} \mathrm{PCQ}=$ Peso de carcaça quente; $\mathrm{PCR}=$ peso da carcaça resfriada; RCQ = rendimento de carcaça quente; $\mathrm{RCR}=$ rendimento de carcaça resfriada; $\mathrm{PPR}=$ perda de peso por resfriamento; $\mathrm{CONF}=$ conformação; $\mathrm{EEn}=$ estado de engorduramento; $\mathrm{CC}=$ comprimento de carcaça; $\mathrm{CP}=$ comprimento de perna; $\mathrm{PP}=$ profundidade de peito; $\mathrm{PPE}=$ profundidade de perna.

Fonte: Elaboração dos autores.

$\mathrm{O}$ fato do peso final dos animais que receberam níveis crescentes de glicerina bruta não ter apresentado influência $(\mathrm{P}>0,05)$ contribuiu para que o PCQ, PCR, RCQ e RCR apresentassem comportamento semelhante, por serem medidas que apresentam estreita ligação com o peso de abate dos animais. Resultados semelhantes foram descritos por Gunn et al. (2010a), ao estudarem níveis crescentes de glicerina bruta $(0,15,30$ e $45 \%)$ na dieta de ovinos confinados sobre o peso de carcaça.

Não houve influência $(\mathrm{P}>0,05)$ dos níveis de glicerina sobre perda por resfriamento. O valor médio desta variável foi de 3,49\%, sendo semelhante aos resultados encontrados por Macedo Júnior et al. (2006), que observaram em cordeiros em pastagem e em confinamento, média de $3,35 \%$ de perda por resfriamento, o que pode indicar a viabilidade do uso de glicerina na terminação de cordeiros.
O termo conformação significa desenvolvimento harmonioso ou proporcional das distintas partes da carcaça (proporção carne e osso), constituindose critério de qualidade comercial das carcaças (COLOMER-ROCHER, 1988). Observou-se que à medida que os níveis de glicerina na dieta foram se elevando, o grau de conformação da carcaça piorou, obtendo-se valores de 3,$7 ; 3,1 ; 3,3 ; 3,0$ e 2,7 de pontuação, sendo classificadas entre muito boa e média. As carcaças dos ovinos que não receberam glicerina bruta na dieta apresentaram melhor qualidade comercial, obtendo-se pontuação de 3,7, próximo ao escore máximo.

$\mathrm{O}$ EEn da carcaça não foi influenciado $(\mathrm{P}>0,05)$ pelos níveis de glicerina na dieta, podendo ser justificado pelo fato do PCF dos animais não apresentarem diferença estatística $(\mathrm{P}>0,05)$ com o aumento dos níveis da GB na dieta. Segundo Santos 
et al. (2001), as curvas de crescimento dos tecidos estão em função do aumento de peso e idade dos animais. Bueno, Cunha e Santos (2000) afirmaram que, com a elevação do peso ao abate, altera-se a proporção dos componentes da carcaça, aumentando as percentagens de gordura, diminuindo as de ossos e pouca ou nenhuma alteração nas percentagens de músculo.

Os valores referentes às medidas de comprimento de perna (CP) apresentaram valor médio de $31,06 \mathrm{~cm}$. Este resultado é similar ao encontrado por Cunha et al. (2008), que apresentaram valores médios de $31,63 \mathrm{~cm}$ de comprimento de perna em ovinos.
Com relação aos valores de comprimento de carcaça (CC), profundidade de peito (PP) e profundidade de perna (PPE), estes apresentaram média de $62,10 \mathrm{~cm}, 25,41 \mathrm{~cm}$ e $13,92 \mathrm{~cm}$, respectivamente. Os cortes da carcaça de pequenos ruminantes variam conforme os costumes regionais, de modo que a paleta e a perna são os principais cortes padronizados na maioria das regiões de criação brasileira (GARCIA, 1998).

As características relacionadas à área de olho de lombo (AOL), textura (TEX), marmoreio (MAR) e cor (COR) não foram influenciadas $(P>0,05)$. Contrariamente, a espessura de gordura apresentou efeito linear decrescente $(\mathrm{P}<0,05)$ com o aumento dos níveis de glicerina bruta na dieta (Tabela 7).

Tabela 7. Características da carne de ovinos alimentados com dietas contendo níveis crescentes de glicerina bruta.

\begin{tabular}{|c|c|c|c|c|c|c|c|c|}
\hline \multirow{2}{*}{ Item $^{2}$} & \multicolumn{5}{|c|}{ Níveis de glicerina $(\%)$} & \multirow{2}{*}{ Equação } & \multicolumn{2}{|c|}{ Valor de $\mathrm{P}$} \\
\hline & 0 & 2,65 & 5,33 & 8,06 & 10,84 & & $\mathrm{~L}$ & $\mathrm{Q}$ \\
\hline $\mathrm{AOL}$ & 15,8 & 13,8 & 15,5 & 15,8 & 13,8 & $\ddot{Y}=14,93$ & 0,614 & 0,864 \\
\hline EG & 3,2 & 2,7 & 3,4 & 2,0 & 2,3 & 1 & 0,025 & 0,746 \\
\hline TEX & 3,2 & 3,1 & 3,1 & 3,0 & 3,0 & $\ddot{Y}=3,08$ & 0,423 & 0,929 \\
\hline MAR & 2,4 & 2,6 & 2,5 & 2,5 & 2,1 & $\ddot{Y}=2,41$ & 0,389 & 0,284 \\
\hline COR & 3,0 & 3,2 & 3,0 & 3,0 & 3,1 & $\ddot{Y}=3,06$ & 0,975 & 0,950 \\
\hline
\end{tabular}

L e Q: efeitos de ordem linear e quadrática. ${ }^{1} \ddot{Y}=3,1611-0,085988 x,\left(\mathrm{R}^{2}=0,47\right) ;{ }^{2} \mathrm{AOL}=$ Área de olho de lombo; $\mathrm{EG}=$ espessura de gordura; TEX =textura; $\mathrm{MAR}=$ marmoreio e $\mathrm{COR}=$ cor.

Fonte: Elaboração dos autores.

A mensuração da área de olho de lombo (AOL) é uma maneira confiável para predizer o crescimento muscular, possuindo alta correlação com o peso de abate dos animais (SAINZ, 1996). No presente trabalho, não foi verificada influência $(\mathrm{P}>0,05)$ dos níveis de glicerina bruta sobre a AOL dos animais, devido ao fato do peso final dos animais também não terem sido influênciados $(\mathrm{P}>0,05) \quad$ (Tabela 5). Resultados semelhantes foram verificados por Gomes et al. (2011) e Gunn et al. (2010a, b), que trabalharam com níveis crescente de glicerina $(0,15$ e $30 \% ; 0,15,30$ e $45 \%$; e $0,5,10,15$ e $20 \%$, respectivamente) na dieta.
Os valores encontrados no presente trabalho, referentes à espessura de gordura, foram influenciados de forma linear decrescente $(\mathrm{P}<0,05)$ e este fato pode ser atribuído ao menor consumo de matéria seca em animais submetidos a dietas com níveis crescentes de glicerina bruta, consequentemente, menor quantidade de energia disponibilizada para deposição de gordura na carcaça.

A carne de ovinos, recebendo dietas com glicerina bruta, obteve classificação, normal de textura; avaliação de marmoreio entre pouco e bom; e cor vermelha claro. Essas características 
estão dentro dos padrões encontrados em carnes comercializadas, indicando que a glicerina bruta não interfere nas características comerciais da carne.

\section{Conclusão}

A utilização da glicerina bruta contendo $43,6 \%$ de glicerol e $6 \%$ de metanol limita o consumo de matéria seca dos animais e, consequentemente, dos demais nutrientes, porém, não influencia no desempenho dos animais e características de carcaça, podendo ser incluída em até $10,84 \%$ na matéria seca de rações para ovinos em confinamento.

\section{Agradecimentos}

Ao meu orientador Jair de Araújo Marques (in memorian); à Universidade Estadual do Sudoeste da Bahia - UESB e ao Programa de Pós-Graduação em Zootecnia da UESB - Campus Itapetinga.

\section{Referências}

ABDULLAH, M.; NAWAZ, H.; MOHIUDDIN, G. Effect of feeding different levels of supplemental tallow on the performance of lactating buffaloes. Journal of Animal Science, Champaing, v. 79, n. 1 p. 119-125, 2001. Supplement 1.

ALLEN, M. S. Effects of diet on short term regulation of feed intake by lactating dairy cattle. Journal of Dairy Science, Madison, v. 83, n. 7, p. 1598-1624, 2000.

AGÊNCIA NACIONAL DO PETRÓLEO - ANP. Resolução n ${ }^{\circ} 42$ de 24/11/2004, Edição Número 236 de 09/12/2004. Diário Oficial [da] União, Brasília, 09 dez. 2004, nº 236, Seção 1, p. 53.

BARROSO, D. D.; ARAÚJO, G. G. L.; SILVA, D. S.; GONZAGA NETO, S.; MEDINA, F. T. Desempenho de ovinos terminados em confinamento com resíduo desidratado de vitivinícolas associado a diferentes fontes energéticas. Ciência Rural, Santa Maria, v. 36, n. 5, p. 1553-1557, 2006.

BERENCHTEIN, B. Utilização de glicerol na dieta de suínos em crescimento e terminação. 2008. Dissertação (Mestrado em Agronomia, Programa Ciência Animal e Pastagens) - Escola Superior de Agricultura Luiz de Queiroz. Universidade de São Paulo, Piracicaba.
BUENO, M. S.; CUNHA, E. A.; SANTOS, L. E. Santa Inês sheep breed in the intensive Lamb meat production in the southeast region of Brazil. In: GLOBAL CONFERENCE ON CONSERVATION OF DOMESTIC ANIMAL RESOUCES, 5., 2000, Brasília. Proceedings... Brasília: EMBRAPA, 2000. CD-ROM.

CASALI, A. O.; DETMANN, E.; VALADARES FILHO, S. C.; PREIRA, J. C.; HENRIQUES, L. T.; FREITAS, S. G.; PAULINO, M. P. Influência do tempo de incubação e do tamanho de partículas sobre os teores de compostos indigestíveis em alimentos e fezes bovinas obtidos por procedimentos in situ. Revista Brasileira de Zootecnia, Viçosa, v. 37, n. 2, p. 335-342, 2008.

CHOI, B. R.; PALMQUIST, D. L. High fat diets increase plasma cholecystokinin and pancreatic polypeptide, and decrease plasma insulin and feed intake in lactating cows. Journal of Nutrition, Bethesda, v. 126, n. 11, p. 2913-2919, 1996.

COLOMER-ROCHER, F. Estudio de los parâmetros que definem los caracteres cuantitativos y cualitativos de lascanales. In: CURSO INTERNACIONAL SOBRE PRODUCCIÓN DE CARNE Y LECHE CON BASES EM PASTOS Y FORRAGES, 1988, La Coruña. Prodeedings... La Coruña, 1988. p. 108.

CUNHA, M. G. G.; CARVALHO, F. F. R.; NETO, S. G.; CEZAR, M. F. Características quantitativas da carcaça de ovinos Santa Inês confinados alimentados com rações contendo diferentes níveis de caroço de algodão integral. Revista Brasileira de Zootecnia, Viçosa, v. 37, n. 6, p. 1112-1120, 2008.

DASARI, M. A.; KIATSIMKUK, P.; SUTTERLIN, W. R.; SUPPES, G. J. Low-pressure hydrogenolysis of glycerol to propylene glycol. Applied Catalysis A: General, New York, v. 281, n. 1-2, p. 225-231, 2005.

DETMANN, E.; VALADARES FILHO, S. C. On the estimation of non-fibrous carbohydrates in feeds and diets. Arquivo Brasileiro de Medicina Veterinária e Zootecnia, Belo Horizonte, v. 62, n. 4, p. 980-984, 2010.

DOPPENBERG, J.; VAN DER AAR, P. The nutritional value of biodiesel by-products (Part2: Glycerine). Feed Business Asia, Beijing, v. 6, n. 3, p. 42-43, 2007.

FARIAS, M. S.; PRADO, I. N.; VALERO, M. V.; ZAWADZKI, F.; SILVA, R. R.; EIRAS, C. E.; RIVAROLI, D. C.; LIMA, B. S. Níveis de glicerina para novilhas suplementadas em pastagens: desempenho, ingestão, eficiência alimentar e digestibilidade. Semina: Ciências Agrárias, Londrina, v. 33, n. 3, p. 1177-1188, 2012.

FERREIRA, M. O. Purificação da glicerina bruta obtida a partir da transesterificação do óleo de 
algodão. 2009. Dissertação (Mestrado em Engenharia Química) - Programa de Pós-Graduação em Engenharia Química, Universidade Federal do Rio Grande do Norte, Natal.

FOOD AND DRUG ADMINISTRATION - FDA. Code of Federal Regulations. Food and drug administration department of health and human services - sudchapter e- animal drugs, feeds and related products. v. 21, p. 582-1320, 2006. Available at: <http://www.accessdata. fda.gov/scripts/cdrh/cfdocs/ cgcfr/CFRSearch.cfm>. Accessed at: 6 out. 2012.

GARCIA, C. A. Avaliação de resíduo de panificação "biscoito" na alimentação de ovinos e nas características quantitativas e qualitativas da carcaça. 1998. Dissertação (Mestrado em Zootecnia) - Faculdade de Ciências Agrárias e Veterinárias. Universidade Estadual Paulista, Jaboticabal.

GOMES, M. A. B.; MORAES, G. V.; MATAVELI, M.; MACEDO, F. A. F.; CARNEIRO, T. C.; ROSSI, R. M. Performance and carcass characteristics of lambs fed on diets supplemented with glycerin from biodiesel production. Revista Brasileira de Zootecnia, Viçosa, v. 40, n. 10, p. 2211-2219, 2011

GUNN, P. J.; NEARY, M. K.; LEMENAGER, R. P.; LAKE, S. L. Effects of crude glycerin on performance and carcass characteristics of finishing wether lambs. Journal of Animal Science, Champaign, v. 88, n. 5, p. 1771-1776, 2010b.

GUNN, P. J.; SCHULTZ, A. F.; VAN EMON, M. L.; NEARY, M. K.; LEMENAGER, R. P.; RUSK, C. P.; LAKE, S. L. Effects of elevated crude glycerin concentrations on feedlot performance, carcass characteristics, and serum metabolite and hormone concentrations in finishing ewe and wether lambs. The Professional Animal Scientist, Champaign, v. 26, n. 3, p. 298-306, 2010a.

KERR, B. J.; DOZIER, W. A.; BREGENDAHL, K. Nutrition value of crude glycerin for nonruminants. In: ANNUAL CAROLINA SWINE NUTRITION CONFERENCE, 23., 2007, Raleigh. Proceedings... Raleigh: Savoy, 2007. p. 8-13.

LAGE, J. F.; PAULINO, P. V. R.; PEREIRA, L. G. R.; VALADARES FILH, S. C.; OLIVEIRA, A. S.; DETMANN, E.; SOUZA, N. K. P.; LIMA, J. C. M. Glicerina bruta na dieta de cordeiros terminados em confinamento. Pesquisa Agropecuária Brasileira, Brasília, v. 45, n. 9, p. 1012-1020, 2010.

LEÃO, J. P.; RAMOS, A. T.; MAROU, V. M.; SOUZA, D. P. M.; NEIVA, J. N. M.; RESTLE, J.; MORON, S. E. Anatomopatologia de amostras de bovinos alimentados com glicerol. Ciência Rural, Santa Maria, v. 42, n. 7, p. 1253-1256, 2012.

LIDDLE, R. A.; GOLDFINE, I. D.; ROSEN, M. S.; TAPLITZ, R. A.; WILLIAMS, J. A. Cholecystokinin bioactivity in human plasma. Molecular forms, responses to feeding, and relationship to gallbladder contraction. Journal of Clinical Investigation, Michigan, v. 75, n. 4, p. 1144-1152, 1985.

LUCHIARI FILHO, A. Pecuária da carne bovina. São Paulo: LinBife, 2000. 134 p.

MACEDO JÚNIOR, G. L.; PÉREZ, J. R. O.; ALMEIDA, T. R. V.; PAULA, O. J.; FRANÇA, P. M.; ASSIS, R. M. Influência de diferentes níveis de FDN dietético no consumo e digestibilidade aparente de ovelhas Santa Inês. Ciência Agrotecnologia, Lavras, v. 30, n. 3, p. $547-$ 553, 2006.

MENTEN, J. F. M.; PEREIRA, P. W. Z.; RACANICCI, A. M. C. Avaliação da glicerina proveniente do biodiesel como ingrediente para rações de frangos de corte. In: CONFERÊNCIA APINCO 2008 DE CIÊNCIA E TECNOLOGIA AVÍCOLAS, 26., 2008, Santos. Anais... Campinas: Fundação APINCO de Ciência e Tecnologia Avícolas, 2008. p. 66-71.

MERTENS, D. R. Gravimetric determination of amylasetreatedneutral detergent fiber in feeds with refluxing in beaker orcrucibles: collaborative study. Journal of AOAC International, Rockville, v. 85, n. 6, p. 1217-1240, 2002.

MORAN, T. H.; MCHUGH, P. R. Cholecystokinin suppresses food intake by inhibiting gastric emptying. American Journal of Physiology, Bethesda, v. 242, n. 2, p. 491-497, 1982.

NATIONAL RESEARCH COUNCIL - NRC. Nutrient requeriments of beef catle. 6 . ed. Washington: National Academy of Sciences, 1984. 90 p.

NATIONAL RESEARCH COUNCIL - NRC. Nutrient requirements of small ruminants. Washington: National Academy Press, 2007. 362 p.

OLIVEIRA, A. S.; CARVALHO, M. R. O.; SOUZA, J. G. Perspectivas na utilização de co produtos do biodiesel na produção de bovinos de corte. In: SIMPOSIO MATOGROSSENSE DE BOVINOCULTURA DE CORTE, 1., 2011, Cuiabá. Anais... Cuiabá: Juscemil Serafim Editora, 2011. p. 129-142.

OLIVEIRA, R. L.; BAGALDO, A. R.; LADEIRA, M. M.; BARBOSA, M. A. A. F.; OLIVEIRA, R. L.; JAERGER, S. M. P. L. Fontes de lipídeos na dieta de búfalas lactantes: consumo, digestibilidade eN-uréico plasmático. Revista Brasileira de Zootecnia, Viçosa, v. 38, n. 3, p. 553-559, 2009. 
OSÓRIO, J. C. S. Métodos para avaliação da produção de carne ovina: "in vivo" na carcaça e na carne. Pelotas: Editora e Gráfica Universitária da Universidade Federal de Pelotas, 1998. 107 p.

PALMQUIST, D. L. Influence of source and amount of dietary faton digestibility in lactating cows. Journal of Dairy Science, Champaign, v. 74, n. 4, p. 1354-1360, 1991.

PALMQUIST, D. L.; JENKINS, T. C. Fat in lactation rations: review. Journal of Dairy Science, Champaign, v. 63, n. 1, p. 1-14, 1980.

PIMENTEL, L. R.; MARCONDES, M. I.; SILVA, M. V.; SIQUEIRA, J. G.; BRAHIM, M. C. Inclusão da glicerina bruta na dieta de vacas da raça Holandesa sobre o consumo, produção e composição do leite. Semina: Ciências Agrarias, Londrina, v. 35, n. 3, p. 1439-1446, 2014.

SAINZ, R. D. Qualidade de carcaças e de carnes de ovinos e caprinos. In: REUNIÃO ANUAL DA SOCIEDADE BRASILEIRA DE ZOOTECNIA, 33., 1996, Fortaleza. Anais... Fortaleza: Sociedade Brasileira de Zootecnia, 1996. p. 3-14.

SANTOS, C. L.; PEREZ, J. R. O.; MUNIZ, J. A.; GERASEEV, L. C.; SIQUEIRA, E. R. Desenvolvimento relativo dos tecidos ósseo, muscular e adiposo dos cortes da carcaça de cordeiros Santa Inês. Revista Brasileira de Zootecnia, Viçosa, v. 30, n. 2, p. 492-497, 2001.
SCHRODER, A.; SUDEKUM, K. H. Glycerol as a by product of biodiesel production in diets of ruminants. Kiel: University of Kiel, 2007. Available at: <http:// regional.org.au/au/gcirc/1/241.htm>. Accessed at: 18 maio 2012.

SILVA, D. J.; QUEIROZ, A. C. Análise de alimentos: métodos químicos e biológicos. 3. ed. Viçosa, MG: Universidade Federal de Viçosa, 2002. 235 p.

SILVA, M. M. C.; RODRIGUES, M. T.; RODRIGUES, C. A. F.; BRANCO, R. T.; LEÃO, M. I.; MAGALHÃES, A. C. M.; MATOS, R. S. Efeito da suplementação de lipídios sobre a digestibilidade e osparâmetros da fermentação ruminal em cabras leiteiras. Revista Brasileira de Zootecnia, Viçosa, v. 36, n. 1, p. 246-256, 2007.

SNIFFEN, C. J.; O’CONNOR, J. D.; VAN SOEST, P. J.; FOX, D. G.; RUSSELL, J. B. A net carbohydrate and protein system for evaluating cattle diets. II. Carbohydrate and protein availability. Journal of Animal Science, Champaign, v. 70, n. 7, p. 3562-3577, 1992.

TYSON,K. S.;BOZELL, J.; WALLACE, R.;PETERSEN, E.; MOENS, L. Biomass oil analysis: research needs and recommendations. In: Technical report national renewable energy laboratory golden. Colorado: [s.n.], 2004. p. 1-116. Available at: <http://www.nrel.gov/docs/ fy04osti/34796.pdf $>$. Accessed at: Acesso em: 20 set. 2012. 